\title{
Safety Grounding Approach for the National Ignition Facility Power Conditioning System
}

\author{
J. Hammon, E. S. Fulkerson, B. Gagnon, R. Anderson
}

This article was submitted to Pulsed Power/Plasma Science-2001 (PPPS-2001)13 $13^{\text {th }}$ IEEE International Pulsed Power Conference (PPC) $28^{\text {th }}$ International Conference on Plasma Science (ICOPS), Las Vegas, Nevada, June 17 - 22, 2001

Lawrence

Livermore

National

Laboratory

June 14, 2001 


\section{Safety Grounding Approach for the National Ignition Facility Power Conditioning System ${ }^{*}$}

\author{
Jud Hammon \\ Titan Corporation, Pulse Sciences Division ${ }^{+}$ \\ 2700 Merced St. \\ San Leandro, CA 94577 \\ Bill Gagnon \\ Brookings Engineering \\ 21729 Hazelcamp Rd. \\ Brookings, OR 97415
}

\author{
E. Stephen Fulkerson \\ Lawrence Livermore Laboratory \\ 7000 East Ave. \\ Livermore, CA 94551-9900 \\ Robert Anderson \\ American Control Engineering \\ 7636 Miramar Rd. \\ San Diego, CA 92126
}

\begin{abstract}
This paper describes a set of analyses and tests performed to evaluate approaches to provide a safe and robust grounding approach for the main Power Conditioning System (PCS) in the National Ignition Facility (NIF) facility presently under construction at the Lawrence Livermore National Laboratory (LLNL). The Power Conditioning System consists of up to 192 capacitor bank modules, each storing $2.2 \mathrm{MJ}$ and capable of producing a peak current over $500 \mathrm{kA}$. The grounding system must minimize touch potentials associated with operation of the Power Conditioning System. In the event of severe faults, the system must assure that the energy delivered to a person through contact with "grounded" structures is very low. Based on computer modeling and low-voltage, lowcurrent tests, we have concluded that the most effective approach is a set of metal enclosures around the output cables (effectively heavy-wall closed cable trays) extending from the capacitor bank modules to their flashlamp loads. This paper will discuss the safety standards identified for this application, the approach to meeting the standards, and the predicted performance of the safety system.
\end{abstract}

\section{INTRODUCTION}

The National Ignition Facility, under construction at the Lawrence Livermore National Laboratory, will include a set of up to 192 high-energy, high-current capacitor bank modules. Each module, located in one of the four Capacitor Bays, drives a set of 20 series pairs of flashlamps, located in the Laser Bays, through a set of 20 high-current coaxial cables. The cables range in length from 66 feet to 180 feet (all cables for a give module will be the same length). Additional details on the system design are discussed in companion papers in this proceedings.

The issue addressed in this paper is the potential for harm to individuals in the NIF facility due to current driven by the capacitor bank modules into grounded structures in the NIF facility. The flashlamp assemblies are isolated from ground, assuring that no significant current will flow in building grounds in normal operation.

No personnel will be allowed in either the Capacitor Bays or the Laser Bays when the PCS Modules are charged or fired. This provides the first level of safety management. However, the PCS modules can drive large currents into grounded structures in the event of a fault from the "hot" conductor of a PCS output cable to a grounded structure in the Laser Bay. To be dangerous, the fault must occur in such a way that very little current can flow back on the return conductor of the affected cable, forcing the fault current to return through the building ground system. This is an unlikely fault, but it could occur, for example, if an output cable was not plugged into the flashlamp assembly but left with its output terminal near a grounded structure in or near the FAU.

If the facility grounding system is not properly designed, a fault of the type described above can result in unsafe voltages applied to grounded structures throughout the NIF facility. Based on a study of international power safety standards, the following grounding safety grounding policy was adopted for the main pulsed power system in the NIF facility:

\section{Administratively prohibit the routing of} conductors into or out of the Capacitor Bay or amplifier region of the Laser Bay without a dielectric break.

- This minimizes the possibility of propagating a touch potential outside of the Laser and Capacitor Bays.

2. Design to keep touch potentials during ground faults less than $500 \mathrm{~V}$.

- This keeps the voltage in a range where skin resistance seems likely to remain in the circuit.

\footnotetext{
The Titan Corporation acquired the pulsed power portion of Maxwell Physics International Company in March, 2001, after the completion of the project described in this paper.
}

This work was performed under the auspices of the U.S. Department of Energy by the University of California, Lawrence Livermore National Laboratory under Contract No. W-7405-Eng-48. 


\section{DISCLAIMER}

This document was prepared as an account of work sponsored by an agency of the United States Government. Neither the United States Government nor the University of California nor any of their employees, makes any warranty, express or implied, or assumes any legal liability or responsibility for the accuracy, completeness, or usefulness of any information, apparatus, product, or process disclosed, or represents that its use would not infringe privately owned rights. Reference herein to any specific commercial product, process, or service by trade name, trademark, manufacturer, or otherwise, does not necessarily constitute or imply its endorsement, recommendation, or favoring by the United States Government or the University of California. The views and opinions of authors expressed herein do not necessarily state or reflect those of the United States Government or the University of California, and shall not be used for advertising or product endorsement purposes.

This is a preprint of a paper intended for publication in a journal or proceedings. Since changes may be made before publication, this preprint is made available with the understanding that it will not be cited or reproduced without the permission of the author.

This report has been reproduced directly from the best available copy.

Available electronically at http://www.doc.gov/bridge

Available for a processing fee to U.S. Department of Energy

And its contractors in paper from

U.S. Department of Energy

Office of Scientific and Technical Information

P.O. Box 62

Oak Ridge, TN 37831-0062

Telephone: (865) 576-8401

Facsimile: (865) 576-5728

E-mail: reports@adonis.osti.gov

Available for the sale to the public from

U.S. Department of Commerce

National Technical Information Service

5285 Port Royal Road

Springfield, VA 22161

Telephone: (800) 553-6847

Facsimile: (703) 605-6900

E-mail: orders@ntis.fedworld.gov

Online ordering: http://www.ntis.gov/ordering.htm

OR

Lawrence Livermore National Laboratory

Technical Information Department's Digital Library

http://www.llnl.gov/tid/Library.html 
3. Design to keep energy delivered to a $90 \Omega$ Ioad (a person where skin resistance is ignored) less than 3 Joules.

- This is $1 / 3-1 / 4$ of the touch-potential energy listed in published energy standards. (See, e.g., References [1] and [2].)

\section{CANDIDATE GROUNDING APPROACHES}

Four basic approaches to meeting this safety objective were identified:

1. Fully insulate the equipment in the Laser Bay, so that a ground fault in the laser bay need not be considered.

2. Float the pulsed power system from facility ground, using a high-value resistor or inductor to provide the safety ground.

3. Tightly bond the PCS module to facility ground, using an improved ground mat in the slab.

4. Tightly bond the PCS module to the grounded laser support structures using a conductive enclosure around the cables.

Approaches 2 and 2 were rejected as being economically impossible to implement in such a way that their safe performance is assured.

Approach 3 was rejected due to the cost of modifying the building design to incorporate a fine ground grid in the slab. Modeling showed that the planned grounding grid, with $4 / 0$ wires on a grid $12.5 \mathrm{ft}$ on a side, would result in touch potentials as high as $3 \mathrm{kV}$ between the PCS module and a fault in the Laser Bay, and still $800 \mathrm{~V}-$ $1,600 \mathrm{~V}$ at significant distances away from this line. The analysis concluded that a grid spacing of 6" would reduce the peak touch potential to $\sim 200 \mathrm{~V}$, likely an acceptable value. Building construction well under way, however, and a modification of the grounding grid was not a practical approach.

This analysis thus focuses on Approach 4; some form of close-coupled grounding structure around the cables from the PCS to the flashlamp assembly, bonded to the PCS modules at one end and to the laser support structures (which must be bonded to the facility ground grid), at the other end.

\section{SUMMARY OF RESULTS}

The touch potentials and the energy delivered to a person through contact with the grounding structures are significantly below the guidelines above for normal shots, for any of the four grounding approaches listed above. Several possible fault conditions, however, can result in much higher voltages and "person energies." As a result, the NIF design includes a cable enclosure system to carry fault currents back to the PCS modules while significantly reducing touch potentials.

A set of calculations was performed to establish the self-inductances and coupling coefficients for a number of geometries for cable trays and cable enclosures. These results, along with laboratory measurements, confirmed that an enclosure around the cables results in the minimum possible touch potential. The outer portion of an enclosed transmission line, such as a coaxial cable or cables inside a conduit, effectively has no inductance, because it eliminates flux outside the enclosure. As a result, only the resistive component of the voltage drop along the enclosure remains.

Based on the calculated inductances, we constructed the SPICE model of the system and used it to estimate voltages, currents, and person energies in the event of a fault from the "hot" terminal of an output cable to the cable tray/enclosure near the Laser bay. For this fault case, we assumed that the fault current reaches the cable tray/enclosure without connecting to the "return" side of the coaxial cable. We modeled four cases; a simple ground plane under the cables (assumed to be approximately $40^{\prime \prime}$ wide), two different cable troughs, and a full cable enclosure.

A highly schematic version of the circuit model is shown in Figure 1. The model assumes that 19 of the 20 flashlamp loads are driven more or less normally, with a breakdown from the remaining cable to a grounded structure near the FAU. Note that the fault of concern, breakdown to ground without involving the cable return conductors, can only occur at the end of the cable, where the cable enclosure is tied to the facility ground through the FAU structures. For example, a "simple" breakdown of an output coax cable would allow return of the fault current to the PCS module through the return conductors of the failed cable. (Very little current would return through any other path in this event.) This constraint was taken into consideration in constructing the circuit model.

The calculated inductances of the cable center conductor and of the return through the cable tray/enclosure are given in Table 1. Table 2 summarizes the results of the SPICE modeling. Example waveforms are given in Figure 2.

Table 1. Wire and Cable Tray/Enclosure Inductances

\begin{tabular}{|l|c|c|}
\multicolumn{1}{c}{$\begin{array}{c}\text { Wire } \\
\text { Inductance }\end{array}$} & $\begin{array}{c}\text { Plate } \\
\text { Inductance }\end{array}$ \\
\hline $\begin{array}{l}\text { Wire 8" above a 40"-wide } \\
\text { plate }\end{array}$ & $43 \mu \mathrm{H}$ & $3.4 \mu \mathrm{H}$ \\
\hline $\begin{array}{l}\text { Wire 1/2" above a 24"- } \\
\text { wide plate }\end{array}$ & $21 \mu \mathrm{H}$ & $0.3 \mu \mathrm{H}$ \\
\hline $\begin{array}{l}\text { Wire 8" above the bottom } \\
\text { of a 10" x 10" Trough }\end{array}$ & $42 \mu \mathrm{H}$ & $1.7 \mu \mathrm{H}$ \\
\hline $\begin{array}{l}\text { Wire 8" above the bottom } \\
\text { of a 24"-Deep Trough }\end{array}$ & $42 \mu \mathrm{H}$ & $0.3 \mu \mathrm{H}$ \\
\hline
\end{tabular}

\section{Cable Trays}

The simplest level of touch potential reduction would be installing a flat conductive cable tray under the cables between the PCS modules and the flash lamp assemblies. The tray would be bonded to the PCS module in the Capacitor Bay and to the support structures in the Laser Bay, which is bonded to the facility ground grid. Both the "hot" and "return" sides of the cables would be isolated 
from the tray for all normal shots, but might break down to the tray in the event of foreseeable faults.

As is shown in Table 2 below, this approach comes close to meeting the Grounding Policy. Voltages are somewhat too high, but person energies are low enough, with a small margin. However, given the difficulty of modeling systems of this complexity, we cannot be confident that the actual system will perform this well. Therefore, this approach was considered too risky.

\section{Cable Enclosures}

To ensure safety of personnel and equipment, the NIF design includes a conducting enclosure around the cables. Our analyses showed that the enclosure need not be fully closed, to achieve the desired effect. For example, the voltage drops are very nearly equal along a 10 " square cross-section enclosed trough or an open-top trough $10^{\prime \prime}$ wide and extending 16 " above the top cable.

Similarly, several bundles of cables can be enclosed in a common "enclosure" using metal plates both above and below the cables. Like the open-topped trough, side walls are not needed if the cables near the outside edges of the "enclosure" are not too close to the opening at the edge.

The selected design is fully enclosed over nearly the entire length of the cable run. However, the design takes advantage of these observations at the ends of the enclosure and at a few short sections where cable sets enter and leave the enclosure. The cable drops from the enclosure to the PCS modules at one end, and to the flash lamp assemblies at the other end are "enclosed" by an array of eight to ten heavy gauge cables.

Table 2 summarizes the results of the SPICE modeling and also includes a comparison between the model results and a test with the prototype First Article PCS module under test at LLNL. Both the model and the test show that the planned approach will meet the safety criteria listed above.

\section{ENCLOSURE DESIGN SUMMARY}

Good current contacts are required between sections of the enclosure, to prevent sparking, even in normal operation, due to eddy currents and the charging of stray capacitances through the enclosure. This means that "casual" contact between sections of the tray/enclosure should be avoided. The selected design ensures that individual pieces will either be separated by a clear gap (1/8" or more) or will be held tightly together. This is achieved by separating adjacent pieces by a nominal $1 / 4$ " and connecting the pieces together with bolted straps. Spacing between the straps could be as much as $2 \mathrm{ft}$ along edges parallel to the current flow direction, but will be approximately 4 " along edges perpendicular to the current flow, to limit current per connection point to less than 50 kA. Straps are formed from $1 / 8$ " thick aluminum for most connections, but use 1/4" copper wire for the transitions at the ramps and for the "drops" to the PCS module and the FAU.

The material used for the enclosure and the thickness of the material have been selected to keep the resistive component of the voltage along the tray to $\sim 150 \mathrm{~V}$ or less. Since the peak current can be as high as $90 \mathrm{kA}$, this means the resistance of the tray/enclosure should be less than $1.5 \mathrm{~m} \Omega$. For the case in which the tray length is approximately $150 \mathrm{ft}$, it would not be possible to meet this resistance budget with steel, and aluminum plate or conduit would have to be at least $1 / 8$ " thick. The selected design uses aluminum plates of $1 / 4$ " thickness for most of the run, with $3 / 16$ " plate used for the bottom plates over the Laser Bay. Sides of the enclosure are formed from aluminum " $\mathrm{I}$ " beams or channel, depending on the locations, with $1 / 4$ " web thickness.

As is shown in Table 2, the fault currents can be in the range of $90 \mathrm{kA}$. High currents mean large forces on the enclosure, requiring adequate structural strength to prevent deformation of the enclosure. Forces in the event of a fault can be as high as $6,000 \mathrm{lb}$ per lineal foot. This, again, argued for the selection of thicker plates for the system.

\section{References:}

1. G. Biegelmeier and W. R. Lee, "New Considerations on the Threshold of Ventricular Fibrillation for $\mathrm{AC}$ Shocks at 50-60 HZ", IEE Proc., 127, part A, 103-110 (March, 1980)

2. IEEE Recommended Practice for Industrial and Commercial Power Systems Analysis (IEEE Std 3991990), Institute for Electrical and Electronics Engineers, New York (1990) 
Table 2. Predicted Voltages, Currents, and Energies for a Cable-to-Tray Fault

\begin{tabular}{|c|c|c|c|c|c|c|}
\hline & \multicolumn{5}{|c|}{20 Capacitors, $180 \mathrm{ft}$ cables } & $\begin{array}{c}24 \text { Caps } \\
66^{\prime} \text { cables }\end{array}$ \\
\hline & $\begin{array}{l}\text { Flat } \\
\text { Cable } \\
\text { Tray } \\
\end{array}$ & $\begin{array}{c}10 \% \text { Deep } \\
\text { Open-Top } \\
\text { Trough }\end{array}$ & $\begin{array}{l}24 " \text { Deep } \\
\text { Open-Top } \\
\text { Trough }\end{array}$ & $\begin{array}{c}\text { Closed } \\
\text { Enclosure }\end{array}$ & $\begin{array}{c}\text { LLNL } \\
\text { Enclosure } \\
\text { Test * }\end{array}$ & $\begin{array}{c}\text { Closed } \\
\text { Enclosure }\end{array}$ \\
\hline Voltage at P. P. Return (V) & 50 & 45 & 20 & 20 & & 30 \\
\hline Voltage at Laser Bay Ground (V) & 460 & 320 & 190 & 190 & 370 & 310 \\
\hline Current in Cable Tray (kA) & 65 & 65 & 65 & 65 & 67 & 92 \\
\hline Current in Ground Grid (kA) & 12 & 6 & 4 & 4 & 5 & 6 \\
\hline Person Energy; Laser Bay end of Cable Tray (J) & 1 & 0.4 & 0.08 & 0.08 & $\sim 0.3$ & 0.22 \\
\hline Person Energy; Laser Bay Ground $(\mathrm{J})$ & 0.4 & 0.2 & 0.04 & 0.04 & $\sim 0.1$ & 0.10 \\
\hline
\end{tabular}

Note: The table gives the cable tray/enclosure current values for the case in which the cable is treated as located only $1 / 2$ " above the metal of the tray/enclosure, as this gives the higher currents, and the voltages and energies for the case of the faulted cable located 8 " above the tray or the bottom of the trough, as this results in the higher voltages, ground grid currents, and energies.

* This column summarizes the results of a set of measurements with the prototype First Article module under test at LLNL. The system has the same architecture as the NIF design, including an enclosed cable tray, and has a set of $180 \mathrm{ft}$ cables. Person energies were estimated based on the closed-enclosure Spice model, scaling the calculated energies with the square of the ratio of measured to predicted voltages.

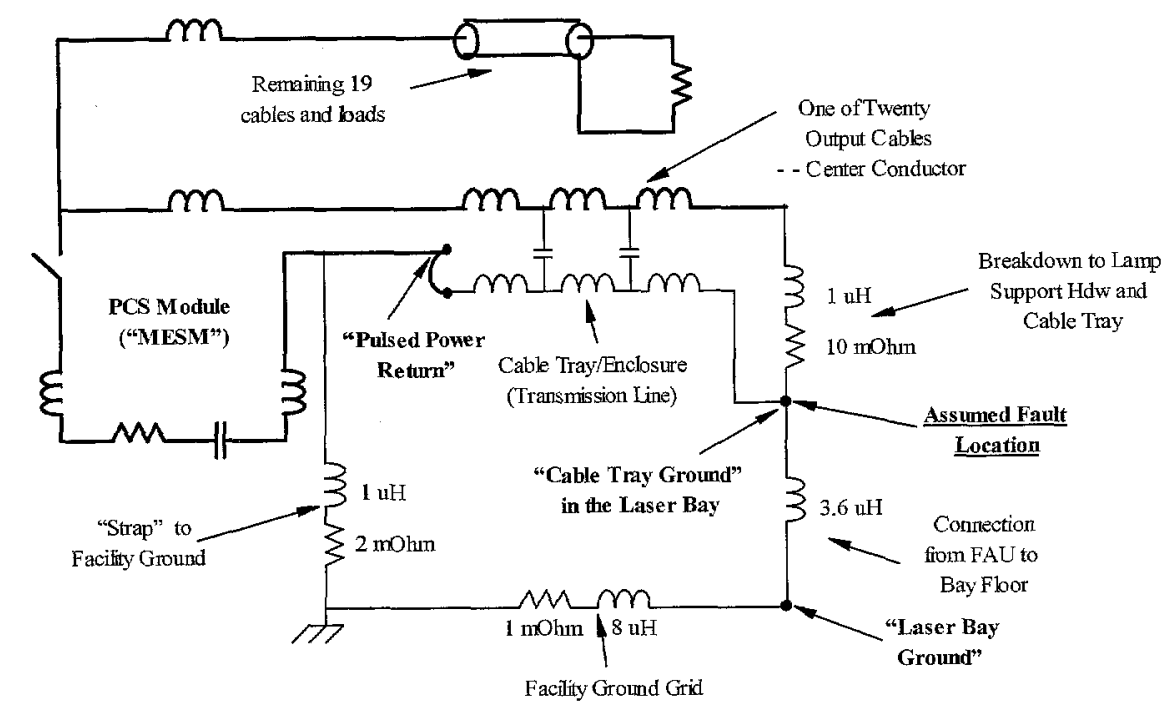

Figure 1. Simplified Circuit Model for the Fault Runs

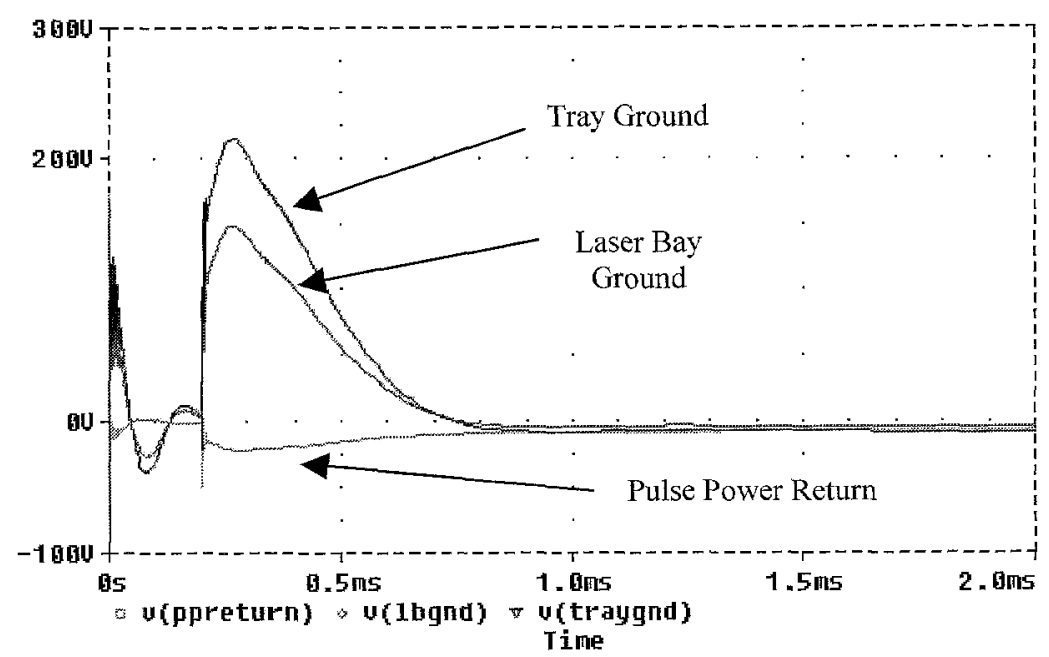

Figure 2. Voltages at three "ground" locations Pulse Power Return, at the PCS Module); Laser Bay Ground; the floor ground grid, in the Laser Bay; and Tray Ground; the cable tray or enclosure, at the Laser Bay end. 